\title{
Diagnosis of health care actions: a territorial analysis from the user's perspective
}

\author{
Rodrigo Moraes Cruz ${ }^{(1)}$ \\ Jacks Soratto(2) \\ Joni Marcio de Farias ${ }^{(2)}$
}
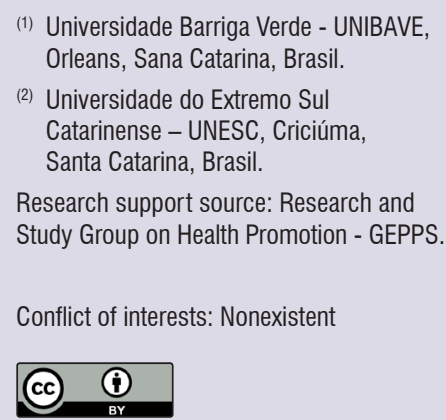

Received on: October 18, 2017

Accepted on: November 1, 2018

Corresponding address:

Joni Marcio de Farias

Rua Madre Tereza Michel, 327 -

Bairro Michel

CEP: 88803-030 - Criciúma,

Santa Catarina, Brasil

E-mail: jmf@unesc.net

\section{ABSTRACT}

Objective: to describe the development of community health actions from the user's perspective.

Methods: a descriptive study carried out in a small city in the south of Brazil, in 2017, with 639 literate residents of both genders. The sample was calculated in a weighted system by neighborhoods, streets and age group, and data were collected by 25 community health workers, distributed into 6 Basic Health Units (UBS). The research instrument included questions about the existence and the awareness of the user about community health education activities. Data were analyzed using the Statistical Package for Social Sciences (SPSS) software version 22.0.

Results: $76.3 \%$ of the participants identified frequent community health actions; of these, $67.3 \%$ had a nurse present and $70 \%$, a community health workers. $63.6 \%$ of the participants thought these actions stimulate the population to reflect on their health and illness, $62.5 \%$ self-care, $66 \%$ health protection measures and $56.4 \%$, believed that these actions influence behavioral changes.

Conclusion: from the perspective of the user, the activities developed fulfilled their expectations about community actions related to health promotion; the results also show that the participants are aware of the actions developed in the city and their significant effectiveness for habits changes. However, the data demonstrate centralized activities that require a re-signification of practices through permanent education on health promotion.

Keywords: Public Policy; Health Promotion; Primary Health Care 


\section{INTRODUCTION}

The Constitution of Brazil, enacted in 1988, establishes the citizen's fundamental rights, which include dignity of the human person and the right to health. This constitutional right was provided through the creation of the Unified Health System in 1990, governed by principles such as universality, equality and integrality ${ }^{1}$. However, to realize the right to health in society, it is necessary to establish public policies to create healthpromoting environments, stimulate community participation, enforce social control, develop personal skills, and reorient health services.

The formulation of public policies is how democratic governments fulfill their purposes and transform electoral platforms into programs and actions that will produce results or changes in the real world ${ }^{2}$. In health, one of the government platforms is the health promotion policy understood as a process that aims to increase the participation of individuals and communities in actions related to the factors (modifiable and unmodifiable) health and quality of life ${ }^{3}$. Therefore, health promotion represents a theoretical and practical path for the global battle against the epidemiological scenario of chronic non-degenerative diseases ${ }^{4}$.

Health Promotion movements began to gain greater prominence in the mid-1970s, with the publication of the Lalonde Report [1976]. The proposals from this report were reinforced at the 1st International Conference on Primary Health Care [1978], held in Alma Ata, Republic of Kazakhstan, and then again at the 1st International Conference on Health Promotion held in Ottawa, Canada, and its subsequent editions ${ }^{5}$.

In this context, in Brazil, one of the strategies adopted was the creation of the National Health Promotion Policy, which establishes attitudes based on cooperation and respect for individuality, encouraging collaboration between sectors and comprehensive care, increasing social participation, establishing co-management mechanisms in the work process and in teamwork and promoting quality of life, all aimed at reducing vulnerabilities and health risks related to health determinants ${ }^{3}$.

The narratives about community health actions reinforce, above all, the strength of popular mobilization. In addition, they evidence improvements in health, progress in the understanding of the broader meaning of health and, consequently, the importance of the engagement of each social actor in health processes 6 .
Community action is understood as the collaborative initiative of a set of social actors in a determined area to try to solve common problems. In a community action, the community dialogues with health teams to establish priority actions for each territory. The present study assesses users' knowledge about the community actions aimed at health promotion developed in their territory, based on the researcher's perspective, aimed at seeing if there is any relation to the premises of health promotion and assessing the role of participants as actors in this process.

This study was carried out based on the need for a reflection on care practices of the city which consider health campaigns as synonymous with health promotion actions, which is understood as a misconception in the perspective of changing behaviors and achieving goals. Given the above, it is essential to diagnose and evaluate public policies proposed by the city. Thus, the present study aims to identify the existence of community actions related to health promotion, from the user's perspective, in a small city in the South region of Brazil.

\section{METHODS}

This is an observational descriptive study that respected all ethical precepts for research with human beings and was approved by the Research Ethics Committee of the University of Extremo Sul Catarinense under protocol $n^{\circ}$. 1.696.968.

The study was carried out in a small city located on the Serra do Rio do Rastro, in the south of Santa Catarina, $188 \mathrm{~km}$ distant from Florianópolis, the capital of the state. The city has approximately 14,250 inhabitants and a per capita income of $\mathrm{R} \$ 678.67$. Currently, the city has 11 schools, of which nine are municipal and two are state schools. The health infrastructure consists of six Basic Health Units (UBS) with full coverage of the Family Health Strategy (FHS), a NASF (Family Health Support Center), a CAPS (Psychosocial Care Center), a municipal hospital and a chemical dependency clinic.

The study included residents of this city, literate, of both genders, who lived in the areas of the Basic Health Units of the neighborhoods Sumaré, Itanema, Guatá, Centro, Arizona and Barro Branco, which have a total population of 12,514 people. The representative sample of the population consisted of 639 participants, distributed by neighborhood, streets and age group, and classified by the area of 25 community health workers (CHW), distributed in six UBS. 
A pilot study was carried out with a sample of 4 instruments for each $\mathrm{CHW}$. All of them received training to apply the instruments. The data collection strategy was based on the distribution of maps of the region with the identification (number) of the houses to be visited for interview, chosen by draw; the residents who were at home were interviewed. The neighborhoods identified represent the city; each neighborhood has a number of households that were randomly selected by house number, without the presence of the CHWs (blinding). When there was no resident in the household, the interview was conducted in the subsequent house with a resident present, in order to guarantee the characterization of the neighborhoods. The criteria for inclusion in the research were: being a resident of the neighborhood, being at home at the time of the interview, completing and signing the consent term and answering the whole research instrument. Residents who were not willing to be interviewed by the community agent were excluded from the study.

The instrument used was a structured, standardized questionnaire, constructed by the researchers according to the prerogative and the purpose of the research, which assessed the users' knowledge about the existence of community health actions, the knowledge of authorship and general characteristics of the behavior-changing actions. All questions were multiple choice (three response options).
Descriptive statistics were used for the characterization of the sample, with absolute values, mean, standard deviation, absolute frequency and relative frequency of the variables studied. The normality of the data was analyzed by the Kolmogorov Smirnov test, and the normal distributions were identified. The proportions in the categories of each variable were verified by not overlapping the confidence intervals, using absolute and relative values. The software Statistical Package for the Social Sciences (SPSS) version 22.0 was used for the organization of the data.

\section{RESULTS}

There was a higher percentage of female participants, $79.9 \%$ against $20.1 \%$ of males. The mean age was $40.7+14.9$ years. After applying the instrument for socio-economic classification, the following classes were identified: A (6\%), B1 (14.8\%), B2 (37.3\%), C1 (20.4\%), C2 (14.7\%), D-E (6.8\%). Regarding the mean age and gender of the participants, the classification by neighborhood is presented in Table 1. The results were organized in three sections that summarize the perception of the phenomenon investigated.

Table 1 shows the characterization of the population, the distribution by gender - showing a higher proportion of females in all the neighborhoods - the representativeness of the neighborhoods by percentage and the mean age of the participants, characterized as young adults.

Table 1. Distribution of the sample by gender, age and neighborhood

\begin{tabular}{cccccccc}
\hline \multicolumn{2}{c}{ Variables } & Sumaré (120) & Itanema (66) & Guatá (140) & Centro (140) & Arizona (71) & $\begin{array}{c}\text { Barro Branco } \\
\text { (90) }\end{array}$ \\
\hline \multirow{4}{*}{ Gender } & Male & 26 & 14 & 46 & 20 & 8 & 12 \\
& $\%$ sample & $4.1 \%$ & $2.2 \%$ & $7.3 \%$ & $3.2 \%$ & $1.3 \%$ & $1.9 \%$ \\
& Female & 94 & 52 & 94 & 120 & 63 & 78 \\
& $\%$ sample & $15.0 \%$ & $8.3 \%$ & $15 \%$ & $19.1 \%$ & $10 \%$ & $12.4 \%$ \\
\hline \multirow{2}{*}{ Age } & Mean & 39.2 & 41.8 & 36.9 & 44.0 & 41.8 & 42.2 \\
& SD & 14.9 & 13.3 & 14.8 & 15.2 & 14 & 15.6 \\
\hline
\end{tabular}

Note: SD $=$ Standard Deviation

To evaluate the knowledge of the participants about the existence of community actions in their territory, from the perspective of the user (Table 2), the data are presented in absolute and relative values for each variable, classified as "unknown", "frequent" or "infrequent" (occurs sometimes). The results showed a considerable frequency of actions known by the community, and which are developed by a health service professional. 
Table 2. Knowledge about the existence of community actions in the territory

\begin{tabular}{lccc}
\hline Variables & n & $\%$ \\
\hline & I don't know & 7 & 1.1 \\
How is the frequency of community actions related to health? & Frequent & 472 & 76.3 \\
& Infrequent & 140 & 22.6 \\
\hline & I don't know & 8 & 1.3 \\
Are there educational actions for the community with the presence of the nurse? & Yes & 413 & 67.3 \\
& No & 193 & 31.4 \\
\hline & I don't know & 6 & 1.0 \\
Are there educational actions developed by the Community Health Worker? & Yes & 432 & 70.0 \\
& No & 179 & 29.0 \\
\hline
\end{tabular}

To identify the type of Community actions (Table $3)$, the instrument presented variables related to the existence of actions with indicators of health promotion and protection, with closed-ended questions with three possible responses ("I don't know", "yes" or "no") which were described by absolute and relative values. The results point to the existence of community actions in the neighborhoods, carried out through campaigns, brochures and personal orientations that provide knowledge and promote the participation of the population.

Table 3. Existence of types of community actions

\begin{tabular}{lccc}
\hline \multirow{2}{*}{ Variables } & & \multicolumn{2}{c}{ Total } \\
\cline { 2 - 4 } & & $\mathbf{N}$ & $\%$ \\
\hline \multirow{2}{*}{ There are community actions that use information and communication resources } & I don't know & 5 & 0.80 \\
appropriate to the local reality & Yes & 391 & 63.5 \\
& No & 220 & 35.7 \\
\hline \multirow{3}{*}{ There are health care actions that seek to relate health problems and living conditions } & I don't know & 8 & 1.3 \\
& Yes & 351 & 57.3 \\
\hline \multirow{2}{*}{ There are community actions that encourage individuals and the community to reflect } & I don't know & 254 & 41.4 \\
\hline on their health and disease conditions & Yes & 393 & 63.6 \\
& No & 223 & 36.1 \\
\hline \multirow{3}{*}{ There are community actions that provide orientation regarding self-care } & I don't know & 7 & 1.1 \\
& Yes & 383 & 62.5 \\
\hline \multirow{2}{*}{ There are community actions that orient the population on health protection measures } & No & 223 & 36.4 \\
\hline \multirow{2}{*}{ There are community actions that guide individuals and the family regarding } & Yes & 6 & 1.0 \\
measures to prevent domestic accidents & No & 405 & 66.0 \\
& I don't know & 3 & 33.1 \\
\hline \multirow{2}{*}{ There are community actions that guide the family and/or people with special needs } & Yes & 437 & 70.8 \\
regarding measures that facilitate their maximum social inclusion & No & 177 & 28.7 \\
\hline
\end{tabular}


Table 4 refers to knowledge about the participation of the population in services, the campaigns identified, the participation in decision-making regarding the confrontation of problems and their self-care, using absolute and relative values for the issues investigated. Community involvement in community actions is observed, a relative change in behavior decontextualized from health promotion.

Table 4. Public policies of promotion and participation of the population

\begin{tabular}{lccc}
\hline \multirow{2}{*}{ Variables } & & \multicolumn{2}{c}{ Total } \\
\cline { 3 - 4 } & & $\mathbf{N}$ & $\%$ \\
\hline \multirow{2}{*}{ There are community actions that use the various sectors in the city to improve the } & I don't know & 7 & 1.1 \\
health of the population & Yes & 332 & 53.9 \\
& No & 277 & 45.0 \\
\hline \multirow{2}{*}{ There are community actions in partnerships with day-care centers, nursing homes, } & I don't know & 7 & 1.1 \\
schools, local merchants, social groups and others & Yes & 371 & 60.2 \\
& No & 238 & 38.6 \\
\hline \multirow{2}{*}{ There are community actions that encourage the participation of people in meetings } & I don't know & 5 & 0.8 \\
of the local health council or other local councils & Yes & 405 & 65.5 \\
& No & 208 & 33.7 \\
\hline \multirow{2}{*}{ These community actions are effective for changing the habits of the population } & I don't know & 23 & 3.9 \\
& Yes & 337 & 56.4 \\
\hline \multirow{3}{*}{ You develop health education activities for the community } & No & 237 & 39.7 \\
& I don't know & 8 & 1.3 \\
\hline
\end{tabular}

\section{DISCUSSION}

It is necessary to rethink health policies regarding the participation of men in this region, since it is not very representative due to the predominant cultural characteristic of considering men as providers of the family. After the implementation of the Family Health Strategy (FHS), the progress made in health care is undeniable, especially regarding health education as a community action. The FHS is based on an expanded view of the biomedical model and of self-care. It stimulates health promotion ${ }^{7}$ and considers territoriality as a precept of effective actions; however, men remain on the fringes of this process.

The data regarding the existence of community actions in the participant's territory (Table 2) indicate that there are frequent community actions/activities related to health, which are carried out mostly by the $\mathrm{CHW}$, followed by nurses. The implementation of community actions in the area of the FHS is of fundamental importance for the construction of an expanded view of health.

Thus, health education practices are inherent to the work of $\mathrm{CHW}$, as their work is centered on health education with emphasis on health promotion ${ }^{8}$. The work carried out by $\mathrm{CHW}$ is aimed at guiding individuals about self-care and protective measures, and stimulating individuals and the community to reflect on their health and illness conditions ${ }^{9}$. In the city where this research was carried out, CHW have a relevant role in the health care of the population. It is worth mentioning that other actions are probably not developed due to the lack of a municipal health education policy, contextualized by territory; with this, the city ends up on the fringes of the National Health Promotion Policy (PNPS) and requires training for all its health workers.

The limitation of the finding highlighted in this section is the need for identification and quantification of the population directly related to the actions developed; the study only points out the existence of the activities in the territories. The tool "health education" is necessary, as it opens dialogue on emerging issues, discussing health information, communication, health problems and life conditions and providing reflections on health and disease conditions and on the relationship between knowledge about self-care and health protection measures. Given the type of community 
actions developed, it is necessary to qualify CHW for this new scenario.

Health education is understood as a social practice that should be centered on the problematization of everyday life, on the appreciation of the experiences of individuals and social groups and on the understanding of different realities ${ }^{10}$. Currently, there is a profusion of new health education proposals at the Basic Health Units (UBS) in Brazil. The actions proposed must include interdisciplinarity, establishment of bonds, cooperation between sectors and strengthening of local democratic management, and must empower individuals and communities in the exercise of their rights related to the improvement of life conditions, providing them with decision-making power in the formulation of public policies, social integration and the capacity to participate in society ${ }^{11}$.

The existence of community actions and the types of activities (Table 3) that link the community with health professionals points out that the users of the services highlighted community actions related to health problems and living conditions; actions that stimulate individuals to reflect on their health and disease condition; guidelines on self-care and health protection measures; and the main strategies and services offered to all. The reality of the city of Lauro Müller is not different from other cities in Brazil in what concerns the development of community actions, where the professional has to improve health education based on the principles of multicausality of the health-disease process and social participation, which includes self-care and autonomy, as opposed to evidence presented in the territory studied.

The participation of the population on planning and the cooperation between different sectors in health and health promotion is pointed out as a determining factor for the effectiveness of these activities. Considering the local situation (day-care centers, nursing homes, schools, local merchants) and the effective social participation in the elaboration, development and evaluation of policies implemented, factors already identified and presented at other times, we evaluate the knowledge of the participants on public policies for health promotion and their participation in community actions, establishing a relationship between different sectors in the city (Table 4). It was observed that users are aware of the association between different sectors for the development of actions that favor health, resulting in partnerships with day care centers, schools, social groups. In addition, it was verified that the participation of the local council and other councils has significant representativeness and that the actions are effective for the change of habits, with involvement of the participants in the development of these actions.

Local and municipal councils have a considerable relevance nowadays, since, besides representing the formal structure of local power, derived from processes of decentralization and municipalization of different public policies, these instances can also become spaces for achieving consensus and agreement with community participation. Legally, they must include the participation of $50 \%$ of the population, since they are spaces to construct policies and demand the guarantee of the right to health.

Educational spaces are firming up health promotion actions; however, the purpose of community health actions in this territory is the establishment of a traditional hegemonic health education model, based on vertical orientations to users (lectures), not considering life histories and different knowledges ${ }^{8,12}$. This perspective reinforces the tendency to pass on information instead of reconstructing meanings collectively, which means that the user is not part of the construction and planning of educational actions and that the health system should use health education to promote health ${ }^{13}$.

The role of community health promotion programs is to encourage people to take responsibility for their own well-being and to build their autonomy, contributing to recovery of function, stability and independence ${ }^{13,14}$ and increasing opportunities, because when personal choice is valued within a program, life satisfaction and pleasure is increased and participants are much more likely to benefit from the results.

In this context, it is necessary to understand health education as a process that must be based on the construction of knowledge in order to change habits, using a set of practices that increase the autonomy of health services users regarding self-care and improve their articulation with professionals and managers of health services. This means that in this educational process all the parties involved (health workers, users and managers) need to recognize themselves as a coherent group in the elaboration of the themes addressed with a focus on education in health ${ }^{13}$.

\section{CONCLUSION}

The study demonstrated the development of community health actions, under the responsibility of $\mathrm{CHW}$ and nurses. There is a lack of intersectorial 
actions and a low involvement of other professionals from the FHS and the community, requiring shared and expanded actions for health promotion. The community actions were associated with the knowledge about these actions, and the factors highlighted were health problems and living conditions, reflections on health and illness, guidelines on self-care and health protection measures. This means that these actions are distant from health promotion, because they emphasize only the disease.

The results obtained from the reflection of the real territorial condition point to the need for qualification and continuous training of health professionals at all levels. The city needs to rethink the actions carried out, which are decontextualized from the national reality and are not effective collaborative strategies for the promotion of healthy habits. Campaigns do not contribute to increase autonomy and empower the population, representing only specific and continuous actions. Therefore, the city must invest in the implementation of a health promotion policy.

\section{REFERENCES}

1. Paiva CHA, Teixeira LA. Reforma sanitária e a criação do Sistema Único de Saúde: notas sobre contextos e autores. Hist. cienc. saudeManguinhos. 2014;21(1):15-35.

2. Souza C. Políticas públicas: uma revisão da literatura. Sociologias. 2006, ano 8(16):20-45.

3. Malta DC, de Castro AM, Cruz DKA, Gosh CS. A promoção da saúde e da atividade física no Sistema Único de Saúde. Rev. Bra. Ativ. Fís. Saúde. 2012;13(1):24-7.

4. Ribeiro AG, Cotta M, Minardi R, Ribeiro SMR. A Promoção da saúde e a prevenção integrada dos fatores de risco para doenças cardiovasculares. Ciênc. saúde coletiva. 2012;17(1):7-17.

5. Marchiori Buss P. Promoção da saúde e qualidade de vida. Ciênc. saúde coletiva. 2000;5(1):163-77.

6. Giugliani C, Rocha CMF, Antunes D, Flores EMTL, Cesa KT, Robinson PG. Série interlocuções práticas, experiências e pesquisas em saúde - Ação comunitária pela saúde em Porto Alegre (recurso eletrônico) -Rede unida. 2016; 1 ed.

7. Araujo MRN, Assunção RS. A atuação do agente comunitário de saúde na promoção da saúde e na prevenção de doenças. Rev. bras. enferm. 2004;57(1):19-25.

8. Costa JSDd, Barcellos FC, Sclowitz ML, Sclowitz IKT, Castanheira M, Olinto MTA. Prevalência de hipertensão arterial em adultos e fatores associados: um estudo de base populacional urbana em Pelotas, Rio Grande do Sul, Brasil. Arq Bras Cardiol. 2007;88(1):54-9.

9. Santos LPGSd, Fracolli LA. O agente comunitário de saúde: possibilidades e limites para a promoção da saúde. Rev Esc Enferm USP. 2010;44(1):76-83.

10. Alves GG, Aerts D. As práticas educativas em saúde e a Estratégia Saúde da Família. Ciênc. saúde coletiva. 2011;16(1):319-25.

11. Carneiro ACLL, Souza Vd, Godinho LK, Faria ICMd, Silva KL, Gazzinelli MF. Educação para a promoção da saúde no contexto da atenção primária. Rev Panam Salud Publica. 2012;31(2):115-22.

12. Goya N. Promoção da saúde, poder local e saúde da família: estratégias para a construção de espaços locais saudáveis, democráticos e cidadãos-humanamente solidários e felizes. SANARE. 2013;4(1):51-6.

13. de Ottawa C. Brasil. Ministério da Saúde. Secretaria de Políticas de Saúde. Projeto Promoção da Saúde. As Cartas da Promoção da Saúde/Ministério da Saúde, Secretaria de Políticas de Saúde, Projeto Promoção da Saúde. Brasília: Ministério da Saúde. 2002.

14. Middleton R, Moxham L, Parrish D. The value of health promotion programs for older people with chronic conditions in the community. Aust Nurs Midwifery J. 2016;24(2):30. 